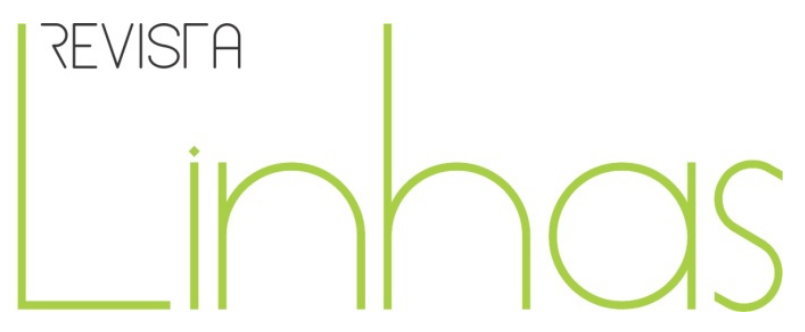

\title{
Norbert Elias e Pierre Bourdieu: biografia, conceitos e influências na pesquisa educacional
}

\begin{abstract}
Resumo
O texto visa a propor uma reflexão sobre Norbert Elias e Pierre Bourdieu, dois dos principais nomes da sociologia do século XX. O primeiro teve sua obra negligenciada durante boa parte de sua vida, ascendendo tardiamente à carreira universitária; o segundo, desde cedo ocupou posição de destaque no campo acadêmico. As trajetórias desses dois intelectuais, vistas de forma comparada, podem fornecer elementos importantes para que suas teorias sejam mais bem compreendidas, além de ser uma oportunidade para refletir sobre como os dois pensadores, com origens sociais diferentes, foram capazes de inscrever seus nomes no cenário intelectual de forma tão marcante, além de serem autores cada vez mais utilizados na pesquisa educacional.
\end{abstract}

Palavras-chave: Norbert Elias. Pierre Bourdieu. Pesquisa Educacional.
José Alexandre Silva

Professor de História da

Secretaria de Estado de

Educação do Paraná - SEED/PR.

sjosealexandre@ymail.com

Luis Fernando Cerri

Doutor em Educação pela

Universidade Estadual de

Campinas - UNICAMP. Professor

da Universidade Estadual de

Ponta Grossa - UEPG.

Ifcronos@yahoo.com

\section{Para citar este artigo:}

CERRI, Fernando Luis; SILVA, José Alexandre. Norbert Elias e Pierre Bourdieu: biografia, conceitos e influências na pesquisa educacional. Revista Linhas, Florianópolis, v. 14, n. 26, jan./jun. 2013. p. 171- 198.

DOI: $10.5965 / 1984723814262013171$

http://dx.doi.org/10.5965/1984723814262013171 


\title{
Norbert Elias and Pierre Bourdieu: biography, concepts and influence in the educational research
}

\begin{abstract}
This paper aims to propose a reflection about Norbert Elias and Pierre Bourdieu, two of the leading names in sociology of the twentieth century. The first one had his work neglected for much of his life, rising late in the university career, while the second one occupied since early a prominent position in the academic field. The trajectories of these two intellectuals, if compared, can provide important elements for a better understanding of their theories, besides being an opportunity to reflect about how these two thinkers, from different social origins, were able to enroll their names in the intellectual scene so markedly, as well as being authors more and more used in educational research.
\end{abstract}

Keywords: Norbert Elias. Pierre Bourdieu.

Educational Research.

\section{Introdução}

Pensar as trajetórias de Norbert Elias e Pierre Bourdieu, e também sobre as formas como estes dois intelectuais inscreveram seus nomes na tradição sociológica, possibilita uma reflexão sobre os diferentes caminhos por eles traçados e, em especial, a forma como suas obras foram apropriadas no Brasil, principalmente na pesquisa educacional. $O$ atraso da publicação das obras de Norbert Elias não é exclusividade brasileira, visto que as edições definitivas de seus principais livros também se deram tardiamente na Europa. 
No caso de Bourdieu, o fato de sua obra ter sido difundida com mais antecedência entre nós brasileiros não significa que tenham sido devidamente exploradas todas as suas potencialidades.

É válido dizer que tanto Elias quanto Bourdieu são filósofos por formação que posteriormente migraram para a sociologia. Ambos atribuíram a guinada a circunstâncias de caráter pessoal - o horror da guerra e a repulsa pela forma como a filosofia era praticada, longe das realidades sociais. Elias, de família judia abastada, serviu a Alemanha na Primeira Guerra. Sua mãe morreu no campo de Auschwitz. Bourdieu, de família humilde, notório desportista, se valeu desta peculiaridade para galgar os degraus escolares. Serviu a França na Guerra da Argélia. Por caminhos diversos, e formulando conceitos parecidos, mas com alguma diferença, ambos se tornaram dois dos intelectuais mais influentes do século XX.

\section{Elementos Biográficos}

Pierre Bourdieu nasceu em 1930, no sudoeste da França, em Béarn. Era filho de um funcionário dos correios. Sua escola fundamental foi realizada com filhos de camponeses, operários e pequenos comerciantes. Cursou o ensino médio em uma cidade vizinha, Pau, onde se destacou nos estudos e ganhou fama como jogador de rúgbi e de pelota basca. Ingressou, posteriormente, na École Normale Supérieure, onde fez sua agrégation em Filosofia (WACQUANT, 2002, p. 96).

De acordo com Jean-François Dortier, citado por Adriane Luísa Rodolpho:

Lá, o jovem provinciano, acanhado e desajeitado, encontra-se imerso em um mundo que não é o seu. Um mundo de jovens burgueses brilhantes, bem falantes, cultivados, à vontade tanto no manejo do verbo quanto da pluma. O jovem Bourdieu, ele, ainda que tenha conseguido subir todos os degraus da hierarquia escolar, não se sente, entretanto, à vontade nem na escrita nem na oratória. E ele não o será jamais. Mesmo que sua obra seja imponente, ele não terá a pluma fácil e alerta; ainda que ele tenha feito centenas de conferências, ele não será um orador. Como Flaubert, a quem ele consagra As regras da arte. Gênese e estrutura do campo literário (Seuil, 1992) a expressão de seu pensamento deve passar pelo esforço permanente de autocontrole, de luta contra si mesmo. Todo o contrário 
da facilidade aparente desses estudantes oriundos da burguesia cultivada que ele encontra na rua de Ulm (RODOLPHO, 2007, p. 7).

Em 1955, passou a lecionar filosofia numa cidade central da França, mas foi convocado para servir militarmente em Versalhes. Como era rebelde, foi punido, sendo enviado à Argélia para servir na missão de pacificação da então colônia norte-africana. “Essa vivência [...] das [...] realidades das guerras travadas pela França contra o nacionalismo argelino mudou o destino [...] de Bourdieu [...] despertou seu interesse pela sociedade argelina [...] e promoveu [...] sua conversão da Filosofia para a Ciência Social." Foi um período em que se aproximou da antropologia. "Ele conjugou a etnografia com estatísticas, a interpretação microscópica com a explanação macroscópica, para mapear o cataclismo social produzido pelo capitalismo colonial e a luta de libertação nacional" (WACQUANT, 2002, p. 97).

Bourdieu trabalhou na universidade de Argel até 1960 "e levou adiante um extenso trabalho de campo lá até 1960, quando o golpe pró-colônia em Argel forçou-o a voar rapidamente a Paris ('liberais' como ele estavam sob ameaça de morte)". De volta de Paris, trabalhou na universidade de Lille. Na Sorbonne, pela primeira vez, leu sistematicamente Marx, Weber e Dhurkeim e apresentou seminários sobre eles. Realizou tal atividade de forma conjugada com a interpretação do material de campo que colheu na Argélia rural e urbana até 1964. Nesse período, tornou-se “Diretor de Estudos da École des Hautes Études en Sciences Sociales e fundou o Centre Européen de Sociologie”. A leitura e a utilização de várias perspectivas teóricas foi algo que se tornou sua marca, pois mesclou "o racionalismo de Bachelard e o materialismo de Marx com o interesse neokantiano de Durkheim pelas formas simbólicas, a visão agonística de Weber sobre os Lebensordnungen em competição com as fenomenologias de Husserl e Merleau-Ponty" (WACQUANT, 2002, p. 98).

Em 1981, Bourdieu chega ao Collège de France. Já era, então, um autor em busca de reconhecimento internacional. Dá grande contribuição a bandeiras como a independência intelectual e a interdisciplinaridade das ciências humanas. Passou ao largo das vaidades intelectuais, ainda mais comuns em Paris, onde realizou um importante 
trabalho editorial na publicação de autores jovens. Também não se furtou a utilizar a mídia quando apoiou maquinistas em greve na estação de Lyon, sendo chamado, na época, de sociólogo do povo, levando a cabo uma intervenção que o classificaria como um intelectual coletivo. Sua morte aconteceu em 2002, deixando como legado uma sólida obra sociológica com leitores espalhados pelo mundo inteiro (RODOLPHO, 2007, p. 9; WACQUANT, 2002, p. 9).

Já Norbert Elias não foi agraciado com reconhecimento no início de sua vida acadêmica. Nasceu em Breslau, parte do território germânico, hoje chamada de Wrocraw (Polônia), no ano de 1897. Originário de uma família de comerciantes judeus, terminou a escola secundária em 1915 e se alistou no exército alemão na Primeira Guerra Mundial, servindo nos fronts leste e oeste e em serviços telegráficos. Em 1917, volta a Breslau e conclui o serviço militar, já estudante de medicina, auxiliando nos serviços de enfermagem (BRANDÃO, 2003, p. 20-21).

Desde jovem, manifestou interesse na carreira de professor universitário, o que não parecia plausível devido à sua religião, conforme passagem de sua entrevista biográfica:

\begin{abstract}
Falávamos na classe de nossos projetos de futuro. Disse que queria ser professor, na universidade, e um de meus colegas de classe disparou contra mim: 'O caminho que leva a esta carreira te foi barrado desde o nascimento.' Grandes risadas do professor e, é claro, de toda a classe. $\mathrm{Na}$ verdade, ele nem me dissera isso por maldade - sua observação era bastante pertinente. Ela me feriu tanto que jamais tive realmente consciência de que essa carreira, sob o reinado do imperador, era praticamente vedada aos judeus (ELIAS, 2001, p. 19).
\end{abstract}

Entre 1917 e 1919, matricula-se nos cursos de filosofia e medicina, optando depois por abandonar a medicina. Em 1924, defendeu sua tese, que havia terminado em 1922, conseguindo o título de doutor em filosofia. A situação econômica desse período, de inflação, arruinou a família de Elias, como também a de outros burgueses alemães. Viu-se obrigado a sustentar seus pais trabalhando em uma fábrica de produtos metálicos. A experiência dessa época, somada à vivência da guerra, influenciou sua determinação de migrar dos estudos de filosofia para a sociologia (BRANDÃO, 2003. p. 26; 33). “[...] depois 
de minha experiência durante a guerra e na fábrica, era natural que eu quisesse fazer estudos que estivessem mais próximos da realidade da vida” (ELIAS, 2001, p. 44).

Quando seus pais voltaram a poder se manter economicamente, Elias partiu para Heidelberg, que era, na época, "uma espécie de meca da sociologia", mas agora na condição de doutor em filosofia. Passou a frequentar os círculos da sociologia, travou contato com Karl Mannheim e se tornou seu assistente: “[...] eu desempenhava uma função de intermediário entre ele e os estudantes; sempre fui mais hábil que ele no contato com os alunos." Também passou a frequentar o salão de Marianne Weber, viúva de Max Weber. Sua tese de habilitação em sociologia, orientada por Alfred Weber, deu origem ao livro A Sociedade Corte (ELIAS, 2001, p. 42-43). Foi então que se deu o primeiro contato de Elias com os autores da sociologia clássica. "Eu passava muito tempo lendo Marx, que nunca lera antes. É claro que ouvira falar de Max Weber mas não o conhecia." "Por ocasião de minha primeira ida a Heidelberg, Jaspers me dera uma certa noção da importância de Max Weber [...]" (ELIAS, 2001, p. 43; 44).

No ano de 1933, Elias decidiu abandonar a Alemanha devido ao contexto político em que o Nacional Socialismo alcançava um poder que lhe parecia perigoso. Destino, França, onde iniciou um trabalho com um fábrica de brinquedos que não deu certo. “[...] abri uma pequena oficina, uma oficina de brinquedos. Comprei algumas máquinas e perdi todo o dinheiro que tinha". Posteriormente, dirigiu-se à Inglaterra, onde conseguiu auxílio de uma bolsa com uma instituição para refugiados. Ali inicia a redação de sua principal obra “O Processo Civilizador”, publicada em 1939 em Basileia, Suíça. Seu temor com a situação na Alemanha se confirmou. A mãe desapareceu no campo de concentração de Auschwitz em 1940 (ELIAS, 2001, p. 58-62).

Em 1939, muda-se para Cambridge. Já havia sido pesquisador visitante em Londres, na London School of Economics. No ano seguinte, foi internado como 'inimigo estrangeiro' na Ilha de Man; depois de liberto, ficou em Cambridge até o final da guerra e se dirigiu para Londres em 1945. Nesse período, trabalhou com análise de grupos, uma técnica criada por um amigo psicanalista, S. H. Folkes, também refugiado, e com educação de adultos. Em 1954, assume um posto de professor de Sociologia em Leicester, onde ficou até se aposentar, em 1962. Nesse ano, aceitou um convite para lecionar na 
Universidade de Gana, onde permaneceu até 1964, quando voltou para Leicester, e continuou organizando e proferindo seminários (BRANDÃO, 2003. p. 48-49).

É comum encontrar a afirmação de que Elias construiu uma teoria original no âmbito sociológico, o que não implica dizer que o fez sem o conhecimento e refutação da obra de autores como Weber, Marx e Freud. No caso de Max Weber, refuta a ideia de líder carismático, a de racionalidade e também a de tipo ideal. No que diz respeito a Marx, considera inapropriados conceitos como superestrutura e ideologia. Com relação à obra de Freud, considera errada a separação entre id, ego, e superego, quando o que importa são as relações e os conflitos entre essas instâncias da personalidade humana (MALERBA, 2011, 184-188).

Interessante notar que Bourdieu vem de origem humilde e alcança ainda jovem o topo da academia, enquanto Elias, que pertencia a uma classe média abastada, por uma série de contingências, somente conseguiu se estabelecer e ter reconhecimento na fase final de sua vida. Ambos possuíam formação inicial em filosofia e atribuíram às suas respectivas experiências, que envolviam guerras, a guinada para a sociologia. Ao que parece, a miséria humana por ambos vivenciada - Bourdieu servindo a França na Argélia e Elias servindo a Alemanha na Primeira Guerra -, talvez em graus diferentes, influenciou suas trajetórias acadêmicas.

Ambos também tinham princípios muito semelhantes no que diz respeito às suas práticas profissionais e à concepção do que um sociólogo deve fazer. Bourdieu se entrincheirava, segundo Wacquant (2002, p. 100):

Contra o fatalismo e as profecias superficiais e novidadeiras do pósmodernismo, ele acreditava não apenas na Ciência Social como um empreendimento do conhecimento, como também na capacidade da Sociologia para informar um "utopismo racional", necessário à salvação das instituições da justiça social da nova barbárie do mercado livre e do Estado retraído. Bourdieu concebia uma Ciência Social unificada como um "serviço público" cuja missão é “"desnaturalizar' e 'desfatalizar”" o mundo social e "requerer condutas" por meio da descoberta das causas objetivas e das razões subjetivas que fazem as pessoas fazerem o que fazem, serem o que são, e sentirem da maneira como sentem. E dar-lhes, portanto, instrumentos para comandarem o inconsciente social que governa seus pensamentos e limita suas ações, como ele incansavelmente tentou fazer consigo próprio. 
Elias (2001, p. 45-46), por sua vez, afirmou, “[... ] eu queria de fato [... ] levantar o véu das mitologias que mascara nossa visão da sociedade, a fim de que as pessoas pudessem agir melhor e de maneira mais sensata; pois tinha a convicção de que uma visão assim deforma o olhar que se tem sobre as coisas". E exemplificou o que acreditava serem mitologias:

Deparei-me com a primeira mitologia ainda criança, vendo o imperador, ouvindo todo o tipo de coisa sobre a grandeza da Alemanha, que igualmente eu lia na Schlesische Zeitung, o diário conservador de Breslau. Ouvia a propaganda nacionalista, a propaganda de guerra, que provavelmente desempenhou um imenso papel; pois quando experimentei a vida no front, as coisas eram bem diferentes da visão que forneciam muitos jornais de guerra. Mais tarde em Heidelberg, pude constatar que as doutrinas dos partidos de esquerda eram quase todas marcadas por idealizações e ideologias equivocadas. Posso então dizer que minha convicção de que é preciso erguer o véu que oculta os conceitos remonta muito longe em meu passado. [...] eu gostava da sociologia porque ela acenava com a possibilidade desse desvelamento".

Ao que parece, nossos dois autores prezavam a possibilidade de que as pessoas simples pudessem agir com mais autonomia, tendo uma consciência mais elevada de suas possibilidades e impossibilidades.

Podemos dizer, tanto de Bourdieu quanto de Elias, que podem ser considerados “estabelecidos e também Out Siders”, cada qual em sua medida. O primeiro vem de um meio mais humilde e conseguiu ter educação escolar privilegiada devido a ser bom atleta. O segundo, embora oriundo de um meio abastado, sentiu na pele o drama de pertencer ao povo judeu no período em que os nazistas tomaram o poder na Alemanha. Ambos tiveram suas existências afetadas por situações de guerra, o que admitiram ter influenciado a decisão de migrar da filosofia para a sociologia. Bourdieu se estabeleceu rapidamente no campo universitário, tornando-se o autor mais citado de sua geração, enquanto Elias, ainda o que valor de sua obra tenha sido notado, só tardiamente desfrutou de reconhecimento. Após essa pequena incursão biográfica, vamos nos concentrar nos principais conceitos e na contribuição teórica dos dois autores para as ciências humanas. 


\section{Norbert Elias e Pierre Bourdieu: alguns conceitos}

Tal reflexão sobre as ferramentas teóricas forjadas pelos autores não constitui, evidentemente, novidade, tendo em vista que muitos acadêmicos renomados buscaram neles "estofo teórico". Quase desnecessário fazer notar também que a aproximação dos dois corpos teóricos foi harmônica, embora, em alguns casos, a interpretação dos conceitos entre esses autores diferentes tenha sido conflitante. Ambos têm sido utilizados com frequência na pesquisa educacional. Bourdieu, mais provavelmente, por ter feito da educação um de seus objetos privilegiados de estudo e por sua obra ter sido difundida antes no Brasil. Já Elias, talvez ainda em viés de consolidação, mas já chamando a atenção dos pedagogos.

Outra questão a ser levada em consideração é o fato de Bourdieu, ao longo de sua vida acadêmica, ter burilado e revisitado seus conceitos, relativizando antigas interpretações conforme amadurecia teoricamente. Elias, por seu turno, depois de escrever "O Processo Civilizador", considerado sua obra máxima, que ganhou uma primeira edição em 1939, só conseguiu dar-lhe uma edição definitiva décadas depois. Viria a escrever mais sistematicamente novos livros depois de voltar de Gana, em 1964, uma fase teoricamente muito produtiva em sua vida. Seus analistas consideram sua obra um todo orgânico. Ele, porém, não teve a preocupação sistemática de ordenar esse todo, deixando a seus intérpretes esse trabalho, muito embora se tenha preocupado em responder a algumas críticas dirigidas à sua primeira obra, “Os Alemães”.

Os livros de Norbert Elias, conhecidos como de primeira fase, são "A Sociedade de Corte" e "O Processo Civilizador". Em ambos, discorre sobre costumes individuais e coletivos que, de acordo com sua teoria, fazem parte do mesmo processo no qual gestos individuais não se desvinculam de uma mentalidade coletiva, ou um habitus. Já na sua introdução de A Sociedade de Corte, Elias levanta a problemática do estudo da sociedade cortesã com conceitos muito caros à sua obra:

Um problema fundamental com que se depara a investigação sociológica da sociedade de corte é a questão de como se constituiu a figuração de homens interdependentes que tornava não só possível, mas também 
aparentemente necessário, que milhares de pessoas se deixassem governar durante séculos ou milênios, repetidamente e sem nenhuma possibilidade de controle da situação, por uma única família ou por seus representantes (ELIAS, 2001, p. 26).

Notemos que o termo figuração é de suma importância; refere-se a uma coletividade humana não-estática e estagnada, mas em constante inter-relação. Isso é justamente o que torna o homo sapiens humano, o contato com outros de sua espécie; cada indivíduo interconectado numa rede de relações com determinações recíprocas, independentemente de sua posição na figuração. Essa interação forma as concepções de eu e nós, de individualidade e coletividade. Elias atribui importância à sociedade de corte pelo motivo de acreditar ter sido no seio dela que foi gestado o refinamento que depois se espraiou pelo restante da sociedade francesa. As sociedades cortesãs serviram de laboratório em que foram gestados e controlados os comportamentos necessários ao atual patamar de desenvolvimento da civilização do Ocidente.

É de tais mudanças dos homens que se trata quando falamos de uma individualização mais intensa, de uma couraça em torno das emoções, de um distanciamento maior em relação à natureza, aos indivíduos e ao eu, [...]. No decorrer da aristocratização e do processo de formação da corte, alteram-se não só as idéias, mas os habitus dos nobres (ELIAS, 2001, p. 246).

O acortesamento dos nobres mudou suas interações e, por conseguinte, a concepção de si. Mudou a forma como eles agiam e sentiam, criando uma nova estrutura de personalidade. Os nobres das cortes de Luís XIV e Luís XV eram da mesma linhagem que seus antepassados, que moravam em seus feudos, distante da corte, e eram responsáveis pela segurança da sociedade. Esses mesmos antepassados utilizavam, à mesa, a mesma faca que podiam utilizar num campo de batalha ou para sangrar um animal numa caçada. Com o surgimento dos Estados Nacionais, os monarcas absolutos abrem mão dos nobres guerreiros, constituindo exércitos profissionais. Àqueles resta viver no jogo da corte com a existência justificada pelo fato de o rei também ser um nobre, "o mais nobre dos nobres". 
Elias descreve a vida na corte desde as suas instalações até a rígida rotina de rituais estabelecida por Luís XV, cerca de cinco por dia. Para um nobre, não ser chamado para participar desses rituais equivalia a desonra e ostracismo. O rei, por sua vez, também era refém dessa rotina, na medida em que a utilizava para controlar a nobreza conforme as sutis necessidades desse jogo de controle.

Para conservar com firmeza em suas mãos as rédeas do poder, tinha de se organizar e manter o controle firme sobre si mesmo. Assim como procurava transformar seu reino, e especialmente o grupo central, a corte, na organização mais previsível e calculável de que podia dispor, também precisava submeter sua própria vida a um ordenamento precisamente calculado e previsível. Sem esse ordenamento, aquela organização não podia funcionar; ela não tinha sentido algum sem ele. [...] Seu despertar ou o momento de ir dormir e seus amores eram ações tão importantes quanto a assinatura de um acordo governamental, e eram configuradas com o mesmo nível de organização. Todas elas serviam em certa medida para manter sua dominação pessoal e sua réputation (ELIAS, 2001, p. 150-151).

$\mathrm{Na}$ sociedade cortesã, a única utilidade do dinheiro era permitir que seus detentores frequentassem os círculos mais altos com o devido requinte e refinamento. De nada valia ter posses se essas não dessem suporte à aparência almejada por seu detentor. Portanto, mesmo esvaí-las para manter as aparências perante outros nobres fazia pleno sentido. Receber bem era crucial para a imagem que se pretendia cultivar; no jogo de poder desse meio, a imagem era essencial. Fosse de outra forma, Luís XIV não teria atrelado à sua figura o próprio Estado, imiscuindo política e vida particular: "O Estado sou eu". Como vimos acima, isso Ihe rendia muito trabalho, pois era necessário o controle constante de seus súditos.

O refinamento da sociedade de corte, para Elias, também representa a fase de um processo do qual nossa sociedade faz uso até hoje. Um período em que já se haviam educado as personalidades a não sucumbir ao ímpeto violento das sociedades guerreiras e medievais. Um mundo em que corpos e mentes haviam sido moldados no mesmo processo. As sociedades cortesãs eram clivadas por sorrisos, jogos de intrigas, mas não de violência física. Assim, como forma de refinamento, a corte francesa, em especial, tinha a característica de acolher em seu seio artistas, como escritores e músicos. 
Valorizava-se a conversação que Elias chamou de civilização. Era aberta a pessoas que não tinham a linhagem da nobreza. Diferente da corte alemã, que não atraiu círculos intelectuais para seu seio.

Em resumo, podemos considerar a corte francesa como uma figuração clivada de indivíduos interdependentes, lutando para manter seu prestígio nas relações de poder. Um ponto no processo civilizador em que os membros da figuração faziam uso de controle de suas emoções, gestado por séculos e demonstrado na civilidade e nas boas maneiras. Esta sociedade cortesã tinha um habitus bastante diferente do de seus antepassados nobres, da sociedade guerreira e da sociedade medieval, afeitos a impulsos e a gestos mais grosseiros. Podemos dizer que, ao longo de gerações, foi gestado um novo habitus, tanto no que diz respeito aos costumes, quanto à organização política, ficando mais evidente em "A Sociedade de Corte" um estudo das relações de poder em uma configuração resultante de um processo de longa duração, que não se acabara naquele momento, mas que continua até nossos dias em pleno curso.

Em “O Processo Civilizador”, publicado inicialmente em 1939, Elias demonstra como surge esse novo habitus que envolve as dimensões sociais e individuais das pessoas no Ocidente a partir do século XV. Como escreve Andréia Borges Leão, "a teoria do processo de civilização aponta para o desenvolvimento conjunto do aparelho psíquico e das cadeias de relações formadas pelos indivíduos na sociedade. A primeira dimensão chama-se psicogênese; a segunda, sociogênese, e ambas encontram-se entrelaçadas" (LEÃO, 2007, p. 21). O próprio Elias afirma que "a psicogênese do que constitui o adulto na sociedade civilizada não pode, por isso mesmo, ser compreendida se estudada independentemente da sociogênese de nossa 'civilização'"' (ELIAS, 1994, p. 15).

Esta perspectiva aponta para o elemento central em sua teoria, segundo a qual o ser humano se faz em interação, ficando evidente pensar o processo civilizador como uma interação coletiva que construiu $\mathrm{O}$ habitus de homens individuais concomitantemente com os habitus nacionais. A perspectiva de Elias não é a do "eu" isolado, mas a do nós, indivíduos que desde a mais tenra infância assimilamos e apreendemos todo o controle mental e das pulsões que nossa civilização cultiva desde várias gerações e que, em dadas circunstâncias, nos causam vergonha ou embaraço. A 
partir desse ponto de vista, não estamos interconectados com outros indivíduos apenas de uma forma espacial, mas também temporal, tendo em vista a longa duração de gestação e maturação dos costumes e práticas sociais que incorporamos. Segundo Elias (2006), citado por Leão (2007, p. 20):

\begin{abstract}
Embora os seres humanos não sejam civilizados por natureza, possuem por natureza uma disposição que torna possível, sob determinadas condições, uma civilização, portanto uma auto-regulação individual de impulsos do comportamento momentâneo, condicionado por afetos e pulsões, ou o desvio desses impulsos de seus fins primários para fins secundários, e eventualmente também sua reconfiguração sublimada.
\end{abstract}

Há de se reiterar ainda que os estudos de Elias focalizam o longo prazo necessário para se perceber as mudanças nas figurações ou configurações sociais. Sem esta perspectiva da longa duração não seria possível valorizar, no conjunto de sua obra, a importância da linguagem. O ser humano se comunica através da linguagem. Para que pudesse haver essa comunicação, foi necessário um longo período no qual o homo sapiens passou por um desenvolvimento do aparato vocal, ao mesmo tempo em que se desenvolvia sua cognição. Evidentemente, a linguagem não é apenas falada. A comunicação por gestos foi utilizada por um longo tempo, de maneira que os hominídeos se fizessem entender.

O mais importante a se destacar acerca da linguagem é que ela é capaz de sintetizar o conhecimento humano gestado por milhões de anos e, na atual fase do Processo Civilizador, uma criança tem de apreender, através da linguagem, o controle e o autocontrole das pulsões conseguido em séculos ou até milênios. A linguagem faz parte da dimensão biológica e social do homo sapiens, tendo em vista que ao longo de sua existência a interação social se dá concomitantemente ao desenvolvimento do aparato vocal, de maneira que ambos os processos se interpenetram.

Assim, poderíamos sumariar as principais contribuições de Norbert Elias da seguinte forma: desde o século $\mathrm{XV}$, o Ocidente passa por um processo civilizador; a humanidade tem como constantes estruturais a interação entre grupos, figurações ou configurações, e um equilíbrio de tensões no interior desses grupos; a melhor perspectiva 
para se observar as mudanças nessas figurações é a longa duração, onde se imiscuem a sociogênese e a psicogênese, como imbricação e interação na formação da psiquê individual e das mentalidades coletivas; tal processo está na base da constituição dos habitus nacionais.

Alguns dos conceitos descritos acima se parecem com as contribuições de Bourdieu, dentre as quais Wacquant destaca, ao longo de toda sua obra, a importância da reflexividade:

[...] seja para transformar continuamente as ferramentas sociológicas em prática científica, seja para refletir criticamente sobre as condições sociais e as operações concretas de construção do objeto. Essa era uma exigência prática incontornável, às vezes mesmo uma questão de vida ou morte, na Argélia beligerante. A necessidade de controlar as distorções que a postura analítica - que Bourdieu denominaria depois "o ponto de vista escolástico" - introduz na relação entre o observador e o observado, entre a vida social real e as observações que o sociólogo produz dela, é um pilar e um tema centrais de sua carreira (WACQUANT, 2002, p. 97).

A reflexividade, também como contribuição de Bourdieu para pensar a relação entre analista e sociedade analisada, ganha muito sendo pensada em conjunto com a sociologia figuracional de Elias. Se estamos habituados a pensar a realidade em opostos binários, de segregação entre sujeito e objeto, entre pesquisador e sociedade, na teoria eliasiana seria um modo falso de pensar a realidade, tendo em vista que o sociólogo, ou qualquer outro cientista social, é parte integrante de seu objeto, a sociedade. Entretanto, isso não implica a esse esquecer que é um cientista social, como afirma o próprio Bourdieu, "O sábio que não sabe o que o define como sábio, isto é, o "ponto de vista escolástico", expõe-se a colocar na cabeça dos agentes sua própria visão escolástica; a imputar a seu objeto o que pertence ao modo de apreendê-lo, ao modo do conhecimento" (BOURDIEU, 1996, p. 203).

Ainda sumariando as contribuições teóricas de Pierre Bourdieu, Wacquant sublinha:

Bourdieu cunhou a noção de capital cultural e inseriu-o em uma concepção generalizada de capital como "energia social" congelada e conversível. Ele recuperou e retrabalhou o conceito aristotélico-tomista 
de habitus para elaborar uma filosofia disposicional da ação como propulsora dos socialmente constituídos e individualmente incorporados "esquemas de percepção e apreciação". Ele forjou a nova ferramenta analítica do campo, designando espaços relativamente autônomos de forças objetivas e lutas padronizadas sobre formas específicas de autoridade, para dar força à estática e reificada noção de estrutura e dotá-la de dinamismo histórico. E ele sociologizou o conceito husserliano de doxa para basear a "atitude natural da vida diária" na coincidência das estruturas sociais e mentais por meio das quais o mundo magicamente aparece como auto-evidente e sua composição é posta além do alcance do debate e da elaboração (WACQUANT, 2002, p. 98).

A concepção bourdieusiana de campo, como um espaço em que forças realizam um jogo no qual se demarcam posições de autoridade e se dinamiza a noção de estrutura, ou o que o próprio autor expõe - “[... ] constituye un sistema de líneas de fuerza: esto es, los agentes o sistemas de agentes que forman parte de él pueden describirse como fuerzas que, al surgir, se oponen y se agregan, confiriéndole su estructura específica en un momento dado del tiempo" (BOURDIEU, 2002, p. 9) ${ }^{1}$ - é muito semelhante ao conceito de figuração em Norbert Elias. "Trata-se de uma rede de relações estruturadas em espaço de posições, mas aberta e constantemente trabalhada pelas contingências históricas, que fazem agora funções de variáveis exógenas e que, por certo, transforma a hierarquia das posições" (MALERBA, 2011. s/p).

O próprio Pierre Bourdieu considera a corte descrita por Elias como um excelente exemplo para explicitar seu conceito de campo:

[...] em La société de cour, capta mecanismos ocultos, invisíveis, baseados na existência de relações objetivas entre os indivíduos ou as instituições. A corte, tal como Elias a descreve, é um belíssimo exemplo do que chamo um campo em que, como num campo gravitacional, os diferentes agentes são arrastados por forças insuperáveis, inevitáveis, num movimento perpétuo, necessário para manter as hierarquias, as distâncias, os afastamentos (BOURDIEU, 2000, p. 48).

Notemos que o conceito de figuração de Elias valoriza o elemento histórico, o efeito das longas durações na constituição do habitus, conceito de campo que Bourdieu

\footnotetext{
${ }^{1}$ Conforme tradução nossa: [...] constitui um sistema de linhas de força, isto é, os agentes ou sistema de agentes que fazem parte dele podem descrever-se como forças que, ao surgir, se opõem e se agregam conferindo-lhe sua estrutura específica em um dado momento do tempo.
} 
leva menos em conta, uma vez que ele centrava sua atenção em elementos do presente. Para Elias, o desenrolar dos fatos do passado tem um papel crucial na rede de relações e na formação da personalidade dos agentes envolvidos. Uma perspectiva de análise com base nas longas durações não poderia se privar desse princípio. O campo bourdieusiano, por seu turno, é descrito como um conjunto de agentes disputando posições de poder, também uma espécie de rede de inter-relações que se conforma e se estrutura de determinada maneira, importando menos a contingência histórica e mais as razões de não mudar facilmente. Tanto a figuração quanto o campo estão perpassados pelo habitus.

Landini, amparada em Casanova (1995), argumenta que a noção de habitus, introduzida na filosofia por Boécio e São Tomás de Aquino, está associada à ideia de que as ações encerram intenções objetivas que ultrapassam as intenções conscientes. Já com Marcel Mauss, a noção de habitus ganha condição de instância sociológica e antropológica dando a esse termo uma natureza social, variável de acordo com indivíduos, sociedades, naturezas e prestígios. Mauss encara o habitus como técnica e como elaboração da razão prática, de maneira coletivizada e individualizada, dando a esse termo uma dimensão corporal e uma produção social. Essas dimensões também são incorporadas por Bourdieu, autor que acrescenta uma articulação deste fenômeno físico às práticas sociais, em particular à esfera ideológico-simbólica das representações e dos valores, formulando a seguinte definição para o termo: capital cultural incorporado e/ou recurso de poder, distribuído de forma desigual na sociedade. "Os habitus constituem princípios de um arbítrio cultural, principalmente na sua acepção de cultura prática: são o sentido prático, o saber prático, evoluindo estrategicamente segundo uma lógica prática entre a acumulação de capital cultural e a legitimação social” (LANDINI, 2007, p. 3; 4).

Já Norbert Elias se refere a habitus individual e a habitus social, significando esse último como uma “segunda natureza'. Assim, o habitus muda com o tempo porque a experiência de uma nação, ou de seus membros, está em processo contínuo de mutação, esta, por sua vez, relacionada com os grupos sociais. Os grupos em posição superior, a fim de se distinguir dos outros grupos, criam novos padrões de comportamento, padrões que, com o passar do tempo, também são adotados pelos outros grupos. “[...] com o 
passar do tempo, os novos padrões de comportamento deixam de ser conscientes para tornarem-se uma segunda natureza - é a essa segunda natureza que se refere quando fala em mudanças na estrutura da personalidade" (LANDINI, 2007, p. 5-6).

O conceito de habitus parece ocupar posições distintas na teoria nos dois autores e um diferencial parece ser novamente a contingência histórica. Déchaux, citado por Malerba (2011, p. 216), oferece uma distinção clara do papel desse conceito na obra dos dois sociólogos:

[...] ambos reconhecem a noção de habitus, mas não lhe atribuem o mesmo lugar na análise. Bourdieu desconsidera a contingência histórica diferentemente de Elias, cujo objeto é claramente histórico, genético; o habitus, por ser "estrutura estruturante e estruturada" para Bourdieu, faz com que nele se conceda um papel, senão ausente, meramente marginal à historicidade. Norbert Elias trabalha uma teoria da civilização; uma vez estabelecido e descrito o processo, a pergunta que se coloca é: porque os habitus evoluem e se transformam? A orientação da sua sociologia é claramente genética: compreender e explicar a gênese do habitus humano. Para Bourdieu, ao contrário, não se trata de explicar o habitus. Mais precisamente, seu objetivo é, uma vez identificado, explicar a imutabilidade das estruturas sociais, e mais ainda a lógica, o "senso prático" das ações que concernem a tal imutabilidade; assim os dois autores se referem a quadros de análise próximos, mas para fins opostos: Bourdieu privilegia as estruturas sociais, dando ênfase ao campo e marginalizando as contingências históricas. Ao contrário, Elias se interessa pela gênese do habitus e as razões de sua evolução.

Dadas as análises, poderíamos dizer que nossos dois autores desenvolvem o conceito de habitus da seguinte forma: a) Elias tem uma visão de longo prazo nas sociedades - figurações -, e pretende explicar a constituição e surgimento dos habitus nessas longas durações. Exemplo claro se dá em seu livro Os Alemães, onde, para explicar a constituição desse povo na sua personalidade e idiossincrasias, retrocede a fatos históricos como a unificação tardia, o desmoronamento do I Reich e a guerra entre Prússia e Áustria. Podemos, neste sentido, a) chamar a análise de Elias de vertical, enquanto se aprofunda na história buscando uma explicação na gênese dos acontecimentos; b) já Bourdieu, ao identificar o habitus, concentra sua análise na imutabilidade das estruturas sociais, mais especificamente em como se dá tal imutabilidade. Se a ênfase de seu olhar recai sobre o campo, privilegiando a relação entre 
os agentes que cristalizam o habitus, podemos dizer que o autor, mais centrado no presente, nos forneceu uma análise horizontal dos fenômenos sobre os quais se debruçou.

Temos, então, em nossos dois autores a utilização do mesmo termo com perspectivas diferentes, mas, pensamos, não excludentes. Elias trabalhou em termos civilizacionais na maioria de suas obras, mas mostrou em "Os Estabelecidos e os Outsiders" como sua teoria também pode servir para pensar nas diferenças de poder em pequenos grupos, como o caso da cidade operária que foi rebatizada, ficticiamente, de Winston Parva. No caso desse estudo específico, o autor chegou à conclusão de que o grupo dominante era o que residia há mais tempo na cidade, o que lhes possibilitara realizar uma rede de relações mais sólidas e lhes permitira excluir os habitantes mais recentes dos cargos de poder e dos lugares de visibilidade. Mais que isso, esses últimos acreditavam de fato que eram pessoas de menor honra e valor que os habitantes mais antigos, graças a mecanismos como a "fofoca depreciativa". Isto pode explicar como uma "mentalidade", ou um habitus, pode ser gerado no curto espaço de algumas décadas e justificar que um grupo, mais esmerado, pudesse manter-se no poder.

Já Bourdieu sempre se dedicou a temas com delimitações menos esparsas de tempo, porém, com uma grande habilidade para conjugar teorias diferentes, o que lhe permitiu caracterizar o conceito de habitus como "capital cultural incorporado". Este, segundo sua teoria, funciona como o cimento que sedimenta a relação entre os agentes no campo e possibilita a realização de análises extremamente argutas para quem os utiliza nos mais variados setores da vida cultural e social. Evidentemente, levar em conta as características diferentes que Norbert Elias e Pierre Bourdieu agregam ao conceito de habitus só pode tornar uma investigação muito mais rica. Uma análise rica e detalhada da conjuntura de um dado campo, nesse caso, não deveria prescindir de como tal situação chegou a esse ponto. A utilização, em conjunto, das ferramentas teóricas propostas pelos dois estudiosos pode ajudar a compreender com maior precisão a conjuntura de um dado objeto, juntamente com uma explicação histórica de longa duração.

\section{Recepção no Cenário Educacional Brasileiro}


Trabalhados alguns elementos biográficos e os principais conceitos de Norbert Elias e Pierre Bourdieu, vejamos agora como esses autores afetaram o meio acadêmico brasileiro, particularmente a pesquisa educacional. Nessa questão, a trajetória de cada um deles é determinante. Bourdieu ganhou relevância no cenário acadêmico desde jovem e suas ideias iniciaram uma tímida penetração na academia brasileira desde o final dos anos 1960. Elias teve seus livros publicados no Brasil a partir da década de 1990 e, desde então, cresce o número de leitores e intérpretes. É necessário mencionar, também, que a área educacional foi objeto privilegiado nas análises de Bourdieu, enquanto Elias não se dedicou exclusivamente ao tema, mas seus conceitos vêm se mostrando bastante frutíferos para os pesquisadores que utilizam sua teoria.

A partir dos anos 1960, Bourdieu formulou uma alternativa teórica abrangente e bem fundamentada sobre o problema das desigualdades escolares. Até meados do século XX, predominava nas ciências sociais uma visão otimista, funcionalista, segundo a qual a escolarização seria crucial na superação do atraso econômico, na superação das desigualdades oriundas das sociedades tradicionais e na criação de uma sociedade mais justa, com base na democracia e na meritocracia. A partir da década de 1960, tal visão entra em crise, por dois motivos: tornou-se imperativo reconhecer que o desempenho escolar não dependia, tão simplesmente, dos dons individuais, mas da origem social dos alunos, além do baixo retorno dos certificados escolares desde a expansão massiva do sistema educacional francês no pós-guerra. Bourdieu afirmou que essa geração foi enganada e enfatizou que a escola, longe de diminuir as desigualdades, a mantinha (NOGUEIRA e NOGUEIRA, 2002, p. 16-17).

Os primeiros sinais da aceitação da obra de Bourdieu vão aparecer na década de 1980. Em estudo que visava a mensurar e perscrutar a penetração de Bourdieu na pesquisa educacional brasileira, Catani et al. (2001, p. 66) chegaram à conclusão que, entre 1979 e 1983, Bourdieu estava na conta de "[...] um autor crítico, mas politicamente desmobilizador: sua teoria, se possibilita instrumentos para a crítica da função desempenhada pela escola na sociedade capitalista, não fornece armas para a ação; limita-se à constatação da dimensão reprodutivista da escola [...]". Era um contexto em que se buscava uma crescente politização nos discursos e teorias educacionais e essa 
concepção a respeito de Bourdieu, de acordo com os mesmos autores, se deveu a cinco aspectos:

\begin{abstract}
a) [...] deu-se pouca atenção ao arcabouço conceitual desenvolvido pelo sociólogo até a época; b) [... ] não parece ter havido a consideração de um dos fundamentos da sociologia de Bourdieu, qual seja, o da existência das mediações e das autonomias relativas entre os campos; c) [...] As proposições do "livro um" de A Reprodução foram [...] cindidas das operações de pesquisa do "livro dois" e [...] tomadas como um discurso genérico sobre a escola, válido para todas as sociedades e em todas as épocas; d) $\mathrm{O}$ quarto aspecto está ligado à criação de expectativas em torno de propostas pedagógicas na obra do autor: na ausência de um discurso doutrinal sobre a educação, ela foi interpretada como "teoria da educação" sem propostas; e) [...] enclausurou-se a sociologia de Bourdieu na dicotomia "reprodução x transformação", dicotomia que na época fez enorme sucesso no campo educacional (CATANI et al., 2001, p. 68-69)
\end{abstract}

Em linhas gerais, podemos afirmar que a recepção que Pierre Bourdieu teve no Brasil, no período indicado, se deveu a uma interpretação fragmentada de sua obra, sem margem para uma interpretação orgânica dos conceitos como os havia proposto. A mutilação tinha por base aquilo que os leitores buscavam ou achavam ser necessário para o contexto político, ainda período ditatorial: uma chave interpretativa que privilegiasse uma ação transformadora para o contexto educacional brasileiro. Tal situação ilustra o quanto podem ser tortuosas as vias da penetração de um autor em outro país.

Há elementos atribuídos à sua obra, particularmente no que diz respeito à dicotomia 'reprodução x transformação', que são contestados. Utilizando termos que lhe são caros (CATANI et al., 2001, p. 69), o próprio Bourdieu afirma: “[...] as resistências individuais e coletivas existem sempre, são componentes não elimináveis do processo de reprodução social." Dessa maneira, o que ele de fato propunha era "[... ] mostrar como se dá a forte adesão dóxica dos agentes sociais à ordem estabelecida e como o sistema de ensino [...] está implicado [... ] nessa cumplicidade impensada, pré-reflexiva, incorporada como uma 'segunda natureza'"; em outras palavras, incorporada como um habitus. É evidente que, se pensarmos apenas em quão dificilmente as relações entre os agentes num dado campo podem estabelecer a mudança de um habitus, podemos perder a perspectiva do que acontece na década de 1990 no campo da pesquisa educacional brasileira. 
A referida dicotomia - 'reprodução x transformação' - envelheceu no final da década de 1980, num processo de “[...] envelhecimento concomitante ao declínio dos modos de análise então mais em voga no campo da pedagogia crítico-social dos conteúdos, pedagogia do oprimido e as variantes então praticadas de marxismo." Entretanto, viria a sair de cena apenas em meados da década de 1990, quando surgem "novas apropriações" da teoria de Bourdieu, que adotam seus conceitos de forma mais orgânica e sistemática ${ }^{2}$. Tinham como uma de suas principais características “[...] o esforço de mobilização dos conceitos e dos modos de trabalho do autor para a análise de questões específicas do espaço da educação." Da mesma forma eram considerados os estudos sobre as "[...] relações entre origem social e expectativas profissionais de futuros professores ou das análises das relações que os professores (de português) mantêm com a questão da leitura". Data desse período também a publicação de sínteses do pensamento do sociólogo francês, situando sua obra no espaço da produção sociológica (CATANI et al., 2001, p. 69; 70; 71).

Pensando ainda na trajetória da aceitação da teoria de Bourdieu no campo da pesquisa educacional brasileira, "nos anos de 1970 e parte dos de 1980", Catani et al. (2001, p. 72) indagam “[...] se essa marca da apropriação do pensamento de Bourdieu entre nós [...] não constitui [...] um dos traços principais da produção educacional, nos obrigando a indagar acerca dos rumos tomados por essa produção, no âmbito [...] da sociologia, [...] da história, da psicologia [...]”. De acordo com o estudo dos autores, podemos dizer Bourdieu teve a plenitude de sua obra negligenciada por supostamente não atender aos interesses mais imediatos dos pesquisadores de então. Ainda de acordo com eles, o que mudou na década de 1990 foi que se passou a valorizar a possibilidade de maior compreensão do espaço no qual se dá a prática educacional.

\footnotetext{
${ }^{2}$ De acordo com os mesmos autores, “[...] a sociologia praticada por Bourdieu somente encontra espaço de inserção efetiva no campo da análise educacional quando do declínio dos modos de análise anteriormente citados e com a reativação dos estudos de sociologia da educação no país: leituras de Basil Bernstein e Bourdieu, nova sociologia da educação de Apple, teoria educacional crítica, estudos de currículo, revista Teoria \& Educação, avaliações do legado de Luiz Pereira e Marialice Foracchi; enfim, quando finalmente se instaura na análise educacional uma pluralidade de pesquisas sociológicas, em objetos e métodos" (CATANI et al., 2001, p. 71).
} 
Quando a obra de Bourdieu começou a ser interpretada de maneira mais apropriada no Brasil é que se deu o início à aceitação de Norbert Elias. Não podemos dizer que isso aconteceu de forma tardia apenas aqui, pois na Europa seus primeiros livros também começaram a ser divulgados apenas na década de 1960. Na França, principalmente, o volume I de O Processo Civilizador chega a se tornar best seller. Ainda não se têm notícias de avaliações da penetração da obra desse pensador no campo educacional brasileiro, mas, considerando a formulação de Brandão (2003) de que nos últimos anos tem chamado a atenção dos pedagogos, arriscamos a dizer que a aceitação está crescendo.

Com o objetivo de corroborar tal afirmação, destacamos a realização, desde 1998, do Simpósio Internacional Processos Civilizadores, que em 2012 chega à $14^{\text {a }}$ edição, principalmente as seguintes: III Simpósio Internacional Processo Civilizador, focalizado na temática "Educação, História e Lazer”; VI Simpósio, com o título História, Educação e Cultura; VII Simpósio, História, Civilização e Educação; XI, "Civilización, cultura e instituciones 3 " (GEBARA, 2012). As edições do evento destacadas por trazer a temática “Educação” no seu título foram, evidentemente, espaços privilegiados para apresentação de trabalhos de pesquisa educacional tendo Norbert Elias como referência teórica.

Elias também sofreu uma interpretação fragmentária desde quando começou a ser publicado no Brasil. Algumas formulações do prefaciador de O Processo Civilizador, Renato Janini Ribeiro, foram duramente criticadas por Jurandir Malerba:

[...] causa certa estranheza o conteúdo dos textos exordiais dos dois volumes das edições brasileiras de $O$ processo civilizador, [...]. Em ambos destila uma dissimulada comiseração por uma suposta ingenuidade de Elias devido a seu apego à categoria de evolução, enfatizando-se como sua grande contribuição o pioneirismo no resgate ao pormenor, à minúcia, ao irrelevante [...] Poderíamos até considerar as maneiras à mesa, os cuidados com o corpo, por exemplo, "pormenores", se não fosse pelo fato de que são peças centrais - a matéria mesma - da análise da evolução da personalidade no Ocidente nos últimos dez séculos. [...]

\footnotetext{
${ }^{3}$ Assim divulgado: "El Instituto de Investigaciones en Ciencias de la Educación, Facultad de Filosofía y Letras de la Universidad de Buenos Aires, por intermedio del proyecto de investigación PICT 17339/04 'Las violencias en la escuela media: sentido, prácticas e instituciones' y el proyecto UBACyT F014/08 'Desigualdad, violencias y escuela: dimensiones de la socialización y la subjetivación', organiza el XI SIPC" (GEBARA, 2012, p. 150).
} 
atribuir valor a essa obra "a despeito" do conceito de evolução, soa a algo como afirmar a contribuição inestimável de Marx à teoria do modo de produção capitalista, "não obstante" seus conceitos de mais-valia ou de luta de classes; ou reconhecesse o vigor do pensamento sociológico de Weber, "apesar" de seu conceito de racionalidade; ou ainda a teoria psicanalítica, apesar do inconsciente (MALERBA, 2004, p. 60-61).

A crítica recai exatamente sobre o fato de o próprio prefaciador das obras dar demonstração de uma leitura fragmentária e pouco fiel ao conjunto da obra do autor prefaciado. Com base no que conhecemos da obra de Elias, acreditamos que o caso se situe além das querelas entre dois intérpretes de um autor e que Malerba tenha razão. Tal situação também ocorreu no meio intelectual francês: entusiasmo e incômodo foi o que ele provocou entre os historiadores. O incômodo é visível em uma mesa redonda realizada em 1995: “[...] A tensão foi resolvida dividindo-se a obra de Elias em partes aceitáveis e não-aceitáveis" (KIRSCHNER, 1999, p. 46). Conclui a autora, na mesma direção de Malerba, tendo em vista que a obra de Elias: “[...] forma um conjunto [de] conceitos [...] relacionados. Daí ser difícil separá-la em partes aceitáveis e inaceitáveis, como se fosse possível atribuir algum valor à sua obra "apesar" da sua ideia de evolução, ou "apesar" a sua teoria dos processos civilizadores" (KIRSCHNER, 1999, p. 47).

Outro aspecto que pode ter prejudicado mais Elias que Bourdieu, devido à francofilia da academia brasileira, é a questão das traduções de suas obras. Sobre a edição brasileira do livro “Os Alemães”, Leopoldo Waizbort aponta alguns elementos:

Ela repete o erro fatal de ser uma tradução de segunda mão: ao invés de traduzir o original em língua alemã, a editora optou por traduzir a tradução inglesa. Os ruídos que se infiltram inevitavelmente em toda tradução reproduzem-se, no caso das traduções das traduções, de modo diabólico. O que poderia ser uma boa solução na versão inglesa muitas vezes leva a uma má solução na versão brasileira. [Um dos aspectos salientados pelo autor é que] Ao invés de "desenvolvimento do habitus", verteu-se "evolução do habitus" um pecado mortal contra Elias, já que um dos objetivos do livro é responder às críticas de evolucionismo que Ihe foram feitas. Elias preocupou-se em distinguir os conceitos de "evolução" e "desenvolvimento": o primeiro está restrito ao âmbito da natureza e das ciências que a tem como objeto; as ciências humanas não podem falar jamais em "evolução", mas apenas em "desenvolvimento". A tradução joga contra Elias e a favor de seus críticos (WAIZBORT, 1998, $\mathrm{s} / \mathrm{p})$. 
A obra de Elias também vem recebendo alguns textos introdutórios, dos quais destacamos Brandão (2003) e Leão (2007). Trata-se de textos cujo objetivo é dar uma visão sintética do pensamento eliasiano, escritas por autores que estiveram ou estão envolvidos com pesquisa educacional. Carlos da Fonseca Brandão oferece uma biografia de Elias; desenvolve os conceitos de figuração e interdependência e investiga dois movimentos educacionais no Brasil à luz da teoria dos processos de civilização: a “Pedagogia Tradicional” e a “Pedagogia Nova”. Segundo esse autor:

Discutindo essa teoria dos processos de civilização em sua totalidade, o controle das emoções, enquanto um dos seus principais elementos constituintes, e relacionando esse controle à educação, de maneira geral, e às teorias pedagógicas de maneira específica, assim como as manifestações desse controle nas práticas pedagógicas modernas, acreditamos que estaremos melhorando nossa compreensão da Educação, sem nunca deixarmos de relacionar os conceitos de civilização e Educação (BRANDÃO, 2003, p. 17).

Já Andreia Borges Leão opta por dividir seu manual introdutório em oito capítulos, nos quais estuda os principais conceitos de Elias; num último, especifica melhor algumas de suas investigações sobre livros infantis que circulavam no Brasil no século XIX. Alguns dos capítulos se dedicam especificamente a livros do autor, como "O Processo Civilizador", "A sociedade de Corte" e "Mozart, a Sociologia de um gênio", de forma a abarcar seus principais conceitos. Acreditamos que o surgimento de tais manuais no mercado editorial se deva a um interesse pelo autor e, ao mesmo tempo, pelo grande papel desempenhado pela difusão de sua obra, na medida em que podem fornecer chaves de interpretação a leitores menos experientes. Bom frisar que ambos os manuais compreendem a obra de Elias como um todo orgânico, oferecendo uma visão geral da obra do sociólogo alemão, abordando seus principais conceitos de forma sintética.

\section{Considerações Finais}

Depois de esboçar alguns elementos biográficos de Norbert Elias e Pierre Bourdieu, aludir a seus principais conceitos e traçar algumas linhas sobre sua difusão e 
utilização na pesquisa educacional no Brasil, resta-nos ainda ensaiar uma pequena conclusão. Ambos os autores têm formação filosófica; são filósofos por formação que enveredam para o campo da sociologia. Essas escolhas, como vimos, estão enraizadas, de acordo com os próprios, em suas experiências trágicas: Elias, servindo a Alemanha na Primeira Guerra; Bourdieu, servindo a França na sua então colônia, a Argélia. Tais experiências fizeram com que se sentissem estimulados a se dedicar a algo mais palpável que a filosofia, como era então praticada, e cada um contribuiu, a seu modo, e em larga escala, para o avanço dessa ciência e das ciências humanas em geral.

Bourdieu teve uma longa carreira acadêmica, tendo a oportunidade de influenciar intelectuais do mundo inteiro, sendo o mais influente de sua geração. Suas pesquisas sobre o contexto educacional francês permitiram-lhe questionar o pensamento de que a escolarização massiva romperia com desigualdades sociais, alçando as pessoas mais talentosas, independentemente de sua condição social, a posições de destaque. Formulou a tese de que, ao invés disso, a educação formal serviria justamente para manter e preservar a ordem social, em razão de que os que desde cedo podem inculcar em seus filhos a importância da escolarização, e, por consequência a importância em adquirir um diploma, são os que mais investem em educação. A análise de Bourdieu certamente encontra bastante eco no Brasil considerando que estamos num país em que a educação pública - a que atende aos setores mais carentes da sociedade - é tratada com grande descaso e que as classes médias se empenham na educação dos seus filhos para, no mínimo, manter a condição social de sua família para a geração seguinte, fazendo uso, para tanto, das redes particulares de ensino, mais aparatadas para proporcionar o conhecimento que pode dar acesso aos cursos universitários.

Elias, que desde criança queria ser um professor universitário, mas em razão das turbulências enfrentadas em sua vida realizou seu sonho só tardiamente, e que, no exílio em fuga da Alemanha nazista, desempenhou outras funções para sobreviver, formulou seu pensamento longe da academia. Teve suficiente persistência para marcar posição mesmo distante do que era mais usual na sua época em ciências humanas e filosofia, criticando duramente as subdivisões disciplinares e a concepção do homem isolado da sociedade e do ser humano isolado da natureza. Pensou as sociedades humanas como 
figurações em que todos estão interligados de maneira que suas ações possam ser percebidas nas longas durações pelo sentido que carregam, ainda que não de forma intencional. Obra frutífera para pensar as vicissitudes da formação de nossa nação inserida num processo civilizador e também para pensar a educação em conjunto com o termo civilização, o que pode enriquecer a compreensão dos mais variados movimentos educacionais brasileiros, como bem o mostrou Brandão (2003).

Norbert Elias e Pierre Bourdieu são autores que desenvolveram um pensamento original e que conseguiram se posicionar ao lado dos grandes clássicos do pensamento ocidental. Wacquant, referindo-se a certo aspecto da obra de Bourdieu, afirma: "Nós mal começamos a perceber sua importância e consumirá anos de trabalho em uma variedade de disciplinas - da Filosofia à Lingüística, da Estética à Sociologia - para extrairmos todas as suas implicações (WACQUANT, 2002, p. 103)." Concordamos com tal formulação. Obviamente, algo semelhante pode ser dito sobre o trabalho de Norbert Elias, cujas contribuições passam longe de ter sido exploradas a contento. Ele próprio defendia que as ciências humanas não dispunham de termos realistas para melhor lidar com a realidade social e que isso demandaria duas ou três gerações de pesquisas e investigações sérias. Certamente, a leitura e o aprofundamento das ideias desses dois autores podem contribuir, e muito, para o avanço geral da pesquisa educacional e das ciências humanas.

\section{Referências}

BOURDIEU, Pierre. Campo de poder, campo intelectual itinerário de un concepto. Sem Local: Editorial Montressor, 2002.

. O Campo Econômico: a dimensão simbólica da dominação. Campinas, São Paulo: Papirus, 2000.

. Razões práticas: Sobre a teoria da ação. Campinas, SP: Papirus. 1996.

BRANDÃO, Carlos da Fonseca. Norbert Elias: formação, educação e emoções no processo de civilização. Petrópolis: Vozes, 2003.

ELIAS, Norbert. Introdução à sociologia. Lisboa: Edições 70, 1970. 
. Os Alemães: a luta pelo poder e a evolução do habitus nos séculos XIX e XX. Rio de Janeiro: Jorge Zahar Ed., 1997.

. Norbert Elias por ele mesmo. Rio de Janeiro: Jorge Zahar ed., 2001.

. O Processo Civilizador. Uma História dos Costumes. v. I. Rio de Janeiro: Jorge Zahar ed., 1994.

. A Sociedade de Corte. Rio de Janeiro: Jorge Zahar ed., 2001.

GEBARA, Ademir. Simpósios Internacionais Processos Civilizadores [SIPC]: Apontamentos Históricos. In: Educação e Fronteiras On-Line. Dourados/MS, v. 1, n. 2, mai./ago. 2011. p.147153, Disponível em:

http://www.periodicos.ufgd.edu.br/index.php/educacao/article/viewFile/1457/pdf_91 Acessado em: 15 set. 2012.

LANDINI, Tatiana Savoia. Jogos habituais - sobre a noção de habitus em Pierre Bourdieu e Norbert Elias. X Simpósio Internacional Processo Civilizador. Campinas, 2007. Disponível em: http://www.uel.br/grupo-

estudo/processoscivilizadores/portugues/sitesanais/anais10/Artigos_PDF/Tatiana_Landini. pdf Acesso em: 30 set. 2012.

LEÃO, Andréa Borges. Norbert Elias \& e a educação. Belo Horizonte: Autêntica, 2007.

MALERBA, Jurandir. Ensaios: teoria, história e ciências sociais. Londrina: EDUEL, 2011.

. A influência intelectual de Norbert Elias. In: Mediações - Revista de Ciências Sociais. v. 9, n. 1/2004. Disponível em:

http://www.uel.br/revistas/uel/index.php/mediacoes/article/view/9047/7572 . Acesso em: 30 set. 2012.

MARCHI JR., Wanderley. Norbert Elias e Pierre Bourdieu: redimensionando as possibilidades de aproximações teóricas. In: X Simpósio Internacional Processo Civilizador, Campinas, 2007. Disponível em: http://www.uel.br/grupo-

estudo/processoscivilizadores/portugues/sitesanais/anais10/Artigos_PDF/Wanderley_Mar chi_Junior.pdf. Acesso em:30 set. 2012.

PEREIRA, Gilson R. de M; CATANI, Denice B; CATANI, Afrânio M. As apropriações da obra de Pierre Bourdieu no campo educacional brasileiro, através de periódicos de área. In:

Revista Brasileira de Educação, n. 17, 2001. Disponível em:

http://www.scielo.br/scielo.php?script=sci_arttext\&pid=S1413-

24782001000200006\&lng=pt\&nrm=iso\&tIng=pt . Acesso em: 30 set. 2012. 
WACQUANT, Loïq J. D.. O legado sociológico de Pierre Bourdieu: duas dimensões e uma nota pessoal. In: Revista de Sociologia Política. Curitiba, n. 19, nov. 2002. Disponível em: http://www.scielo.br/scielo.php?script=sci_arttext\&pid=S010444782002000200007\&lng=pt\&nrm=iso . Acesso em: 30 set. 2012.

WAIZBORT, Leopoldo. Questões não só alemãs. In: Revista Brasileira de Ciências Sociais. São Paulo, v. 13, n. 37, jun. 1998. Disponível em:

http://www.scielo.br/scielo.php?script=sci_arttext\&pid=S0102-

69091998000200010\&lng=pt\&nrm=iso . Acesso em: 30 set. 2012.

RODOLPHO, Adriane Luísa. Pierre Bourdieu: notas biográficas. In: Protestantismo em Revista. v. 14, set./dez. 2007. Disponível em:

http://www3.est.edu.br/nepp/revista/014/ano06n3_01.pdf. Acesso em: 30 set. 2012.

Recebido em: 29/01/2013

Aprovado em: 01/04/2013

Universidade do Estado de Santa Catarina - UDESC Programa de Pós-Graduação em Educação - PPGE

Revista Linhas

Volume 14 - Número 26 - Ano 2013 revistalinhas@gmail.com 